\title{
The long path to achieving green economy performance for micro small medium enterprise
}

\author{
Astadi Pangarso $^{1^{*} \mathbb{C} \text {, Kristina Sisilia }}{ }^{1} \mathbb{B}$, Retno Setyorini ${ }^{1} \mathbb{B}$, Yahya Peranginangin² and Agni Alam Awirya $^{3}$
}

\author{
${ }^{*}$ Correspondence: \\ astadipangarso@telkomuniversity. \\ ac.id \\ ${ }^{1}$ Business Administration \\ Department, Telkom University, \\ Bandung, Indonesia \\ Full list of author information is \\ available at the end of the article
}

\begin{abstract}
Micro small medium enterprises (MSMEs) play an important role in a country's economy, so managers must try to run their business according to the current concept of the green economy (GE). Green economy is an economic concept that makes environmental sustainability an important part of realizing sustainable development goals (SDGs). The performance of MSMEs in terms of GE is a measure of how successful an MSME is in implementing the GE concept. Apart from GE, an equally important element regarding MSMEs is business digitization/digitalization. In the era of society 5.0, MSMEs are increasingly affected by digital technology while running their business. With digitalization, MSME managers can run their company in a more environmentally friendly way to align with the GE concept. Not all MSMEs are ready to implement the GE concept and digitalization, which is a serious problem that deserves attention. To produce a tangible solution related to the implementation of the GE concept and digitization requires a literature review. The literature review helps identify research gaps and formulate a theoretical process in terms of MSME readiness regarding the implementation of the GE concept and digitalization to the performance of GE MSMEs. There is still a limited research framework that comprehensively explains the readiness process related to the GE concept. The digitization of MSMEs on GE's performance is the background of this research. This study aims to develop a research framework for GE MSME performance related to MSME readiness related to the GE concept and digitalization. The research method uses a literature review, and summative content analysis for secondary data in Scopus indexed scientific research publication documents in English, which can be downloaded and relevant until March 2021. The research framework formed consists of 15 constructs for 15 propositions derived from 16 publication documents, using Scopus indexed articles. This research framework contributes to the study of entrepreneurship in general and GE's performance for MSMEs. The research framework formed because of the findings of this study is helpful as a basis for empirical research in the future.
\end{abstract}

Keywords: Green economy, Digitalization, MSME, Innovation, Quintuple helix

\section{Introduction}

Green economy (GE) is an ideal concept that harmonizes the economy, the environment (low carbon), and human society, to ensure life on earth can continue in a sustainable manner (UNEP, 2011). The GE concept plays an important role in responding to three challenges (environmental, social, and economic) to achieve sustainable development priate credit to the original author(s) and the source, provide a link to the Creative Commons licence, and indicate if changes were made. The images or other third party material in this article are included in the article's Creative Commons licence, unless indicated otherwise in a credit line to the material. If material is not included in the article's Creative Commons licence and your intended use is not permitted by statutory regulation or exceeds the permitted use, you will need to obtain permission directly from the copyright holder. To view a copy of this licence, visit http://creativecommons.org/licenses/by/4.0/. 
(Bag et al., 2020). Considering GE is associated with sustainability based on strength and weakness, the topics related to the above (GE and sustainability) include cleaner production, waste management, product-service systems, nature-based solutions, and industrial circular economy ecology. The theory underlying the GE concept comes from environmental economics and economic ecology (Loiseau et al., 2016). From the perspective of environmental economics and economic ecology, the GE concept has six main topics that are discussed in a sequence that is more specific to those previously mentioned, namely: (1) sustainable development; (2) green investment in urban areas; (3) tourism, business, education, and human resources; (4) renewable energy production; (5) the 3Rs (recycle, reduce, reduce) for product cycles; (6) conservation. All the topics mentioned above relate to the business sector in general. The GE concept is a complete umbrella concept for all ecological processes (not only from a resource point of view). The completeness of the GE concept can be seen from the fact that it 'overshadows' other concepts, such as the circular economy (CE) and bio-economy (D'Amato et al., 2017).

Micro small medium enterprises (MSMEs)/small medium micro enterprise (SMME) have an important role in the economic progress of a nation (Khurana et al., 2021). MSMEs have a broader scope than SMEs, because SMEs are part of MSMEs. Within MSMEs, there is a micro-enterprise category with 5-10 employees working under capital conditions that tend to be less 'bankable.' Hence, the study of MSMEs provides a comprehensive picture of "small" businesses. In the era of society 5.0, digital technology plays a significant role in almost all aspects of human life, including MSMEs. Apart from GE, digitalization also plays an important role in realizing sustainability (Castro et al., 2021). Therefore, digitalization and GE are related to each other to realize sustainability. To be able to implement the GE concept as well as digitize it, MSMEs need to be prepared. Dutta et al. (2020) stated the importance of the readiness of MSMEs to implement digitalization. Meanwhile, Singh et al. (2018) examined the antecedents of MSME readiness in implementing GE. Researchers suspect the readiness of MSMEs relates to GE and digitalization to influence the performance of GE MSMEs as an organization. The measure of the success or failure of an MSME in implementing the GE concept is seen in its organizational performance related to GE. Based on searches the authors conducted on the Scopus database until March 2021, there were limited research publications on GE's performance for MSMEs. Previous research that examined GE's performance was in the context of large companies that have implemented GE practices, as has been done by El-Kassar and Singh (2019), Yang et al. (2017), and Zhan et al. (2018) examine various types of business organizations including SMEs but not MSMEs. GE's performance as described by El-Kassar and Singh (2019), Yang et al. (2017), and Zhan et al. (2018) also uses the operationalization of performance variables that are not specifically GE's performance, because they have not combined economic (financial), environmental and social elements in a complete research construct.

The research of Singh et al. (2018) and Dutta et al. (2020) discusses the GE's readiness and digitalization for MSMEs. There has been no previous research examining the readiness of MSMEs to implement the GE concept and digitalization, so this has become a fairly serious problem. A tangible solution related to the implementation of the GE concept and digitization requires a literature review to theoretically develop a process 
from the readiness side of MSMEs related to implementing the GE concept and digitization until its impact on the performance of GE MSMEs. As far as the authors know, there is no research framework related to the readiness process (path of influence) for implementing the GE concept and digitalization as an antecedent of GE's organizational performance for the context of MSMEs. This raises the question: "what kind of research framework is built to explain the process (path of influence) readiness for the implementation of the GE concept, as well as digitalization, as an antecedent of GE's organizational performance for the context of MSMEs?".

\section{Method}

The research is based on literature studies and summative content analysis using secondary data that only comes from sources of Scopus indexed research publications considering that the Scopus database can provide quality scientific articles that are also reliable in addition to the Web of Science (WoS) (Gatto \& Re, 2021; Kirillova, 2017). The literature review of this research is a method according to the research objective, namely, to develop a research framework based on previous research gaps relevant (miner approach and spotting research gaps review strategy), recent, and derived from quality literature sources (Breslin \& Gatrell, 2020). The literature review in this study includes a domain-based view and a method-based view (Paul \& Criado, 2020). It aims to develop a research framework through a classically structured review to identify and integrate research gaps (integrative/critical review) in tabular form (Snyder, 2019), while limiting the selection of scientific publications to those using quantitative research methods, using structural equation modeling (SEM) data analysis tools. Quantitative research was chosen, because it tends to produce generalization-type findings, making it more appropriate to develop a research framework.

Furthermore, SEM-based research was chosen, because it can more clearly state the influence between constructs in a research framework. It is divided into two types, namely, variance and covariance. The authors also included the phrase PLS or partial least square as part of the document search limitation in this study. This meant that the collected documents could more fully cover both covariant and variant SEMs. In addition, PLS is a variant-type SEM that has been widely used in business research and recent Scopus indexed journal publications (Cepeda Carrión et al., 2016; Hair et al., 2012; Richter et al., 2016).

The first step in this literature review was to enter two keyword packages to find articles relevant to the research topic on MSMEs. The literature review contains decisions regarding including scientific research documents that meet the criteria for consideration (Breslin et al., 2020). The first inclusion research context close to MSMEs was also used (articles from scientific journals publication documents). Searches for specific keyword packages were used with the following criteria for the next scientific publication documents inclusion: they had to be downloaded in full articles, in English, and published by March 2021. The second step was to conduct a literature review for each keyword package based on the examination of titles, abstracts, keywords, and efforts. The research is in the context of MSMEs/SMEs and summative content analysis relevant to each keyword package to enter the analysis stage. The criteria-eligible documents included articles that discuss (state explicitly) words and/or phrases about: green 
economy; performance; digitization; readiness; SEM; and PLS. So, if after reading one by one there are articles that: do not explicitly state research related to the green economy; performance; digitization; readiness; SEM; and PLS also will be excluded (deleted/ not included for more detailed review). The third step was to analyze each published research article included in the paper (pertinent documents of a table) to identify the research gap related to the influence between constructs, and then arrange a sequence of relationships between constructs into a unified research framework/conceptual framework (Webster \& Watson, 2002). Lumban Gaol (2021) states that the number of research publication documents analyzed and or synthesized in a systematic literature review has the potential to be relatively small (less than 50 ). Figure 1 describes the research protocol related to the literature review process.

The introduction states that there are two main topics of this research, namely, GE and digitalization. The following is a discussion of the articles for each keyword package.

1. "green economy" AND "PLS" OR "partial least square" OR "SEM" OR "structural equation modeling." Based on the search until March 2021 using a combination of the keywords above, 19 research publication documents were found. Of the nineteen previous relevant studies related to GE and an exciting research gap, only eight papers were found. Relevant documents include research conducted by: Sobaih et al. (2020); Chung (2020); Asadi et al. (2019); Yarimoglu and Binboga (2019); Yen (2018); Han et al. (2018); Singh et al. (2018); and Wong et al. (2018). Research Sobaih et al.

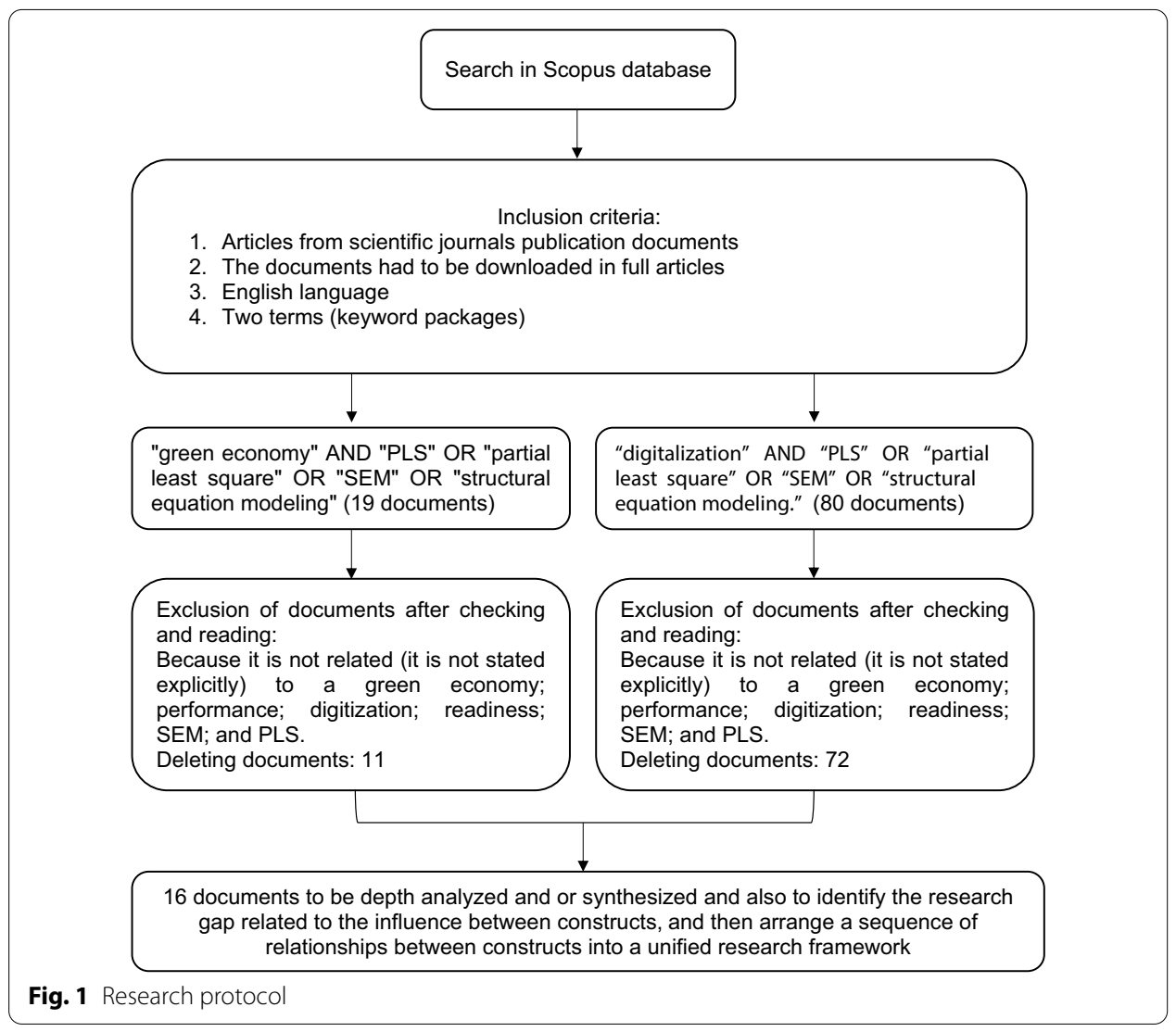


(2020) found that GE-based human resource management affects GE-based innovation and organizational performance related to the environment in the context of a small-scale lodging company in Cairo, Egypt. Research by Chung (2020) revealed the important role of external stakeholder pressure on GE-oriented organizational strategies in the hotel context in Taiwan. Research Asadi et al. (2019) found the antecedents of intention to adopt the GE concept in manufacturing companies, while Yarimoglu \& Binboga's research (2019) found the important role of environmental concern and altruism towards GE-based behavior in Turkey. Yen's research (2018) discovered that external stakeholder pressure affects GE-based leadership commitment and collaboration in electronics manufacture companies in Taiwan. Meanwhile Han et al. (2018) found that social norms influence environmental awareness for cruise ship passengers. The research by Singh et al. (2018) found antecedents of MSME readiness to run a GE-based business in India. At the same time, Wong et al. (2018) found that the GE-based business strategy influences organizational performance related to the environment for manufacturing companies in India. Of the eight documents that examine the context of MSMEs, only the research was conducted by Singh et al. (2018). The other eight documents were also analyzed and helped develop the research framework considering their subject matter was still in the business research area, and they had been published in reputable journals, relatively recently, and researched constructs that were appropriate as part of the research framework.

2. "digitalization" AND "PLS" OR "partial least square" OR "SEM" OR "structural equation modeling." Using a combination of these keywords, 80 research publication documents were found.

Of the 80 relevant studies related to the digitization of MSMEs, only eight documents were found. These included research conducted by: Garzella et al. (2021); Alraja et al. (2020); Najib and Fahma (2020); Irimiás and Mitev (2020); Khin and Ho (2019); Somjai et al. (2019); Bouwman et al. (2019) and Tajudeen et al. (2019). Meanwhile Garzella et al. (2021) found that digitalization influences MSME innovation in Italy. Meanwhile Alraja et al. (2020) found the antecedents of the digitization of MSMEs in Oman. Najib and Fahma's research (2020) found antecedents of awareness of food and beverage MSMEs in Indonesia related to digitalization in terms of payments. Irimiás and Mitev (2020) found that digitalization indirectly affects MSME business performance in Hungary. Khin and Ho (2019) found that the digital orientation and digital capabilities of IT SMEs in Malaysia influence digital innovation and organizational performance. Research Somjai et al. (2019) found the moderating effect of digitization on the performance of MSME organizations in Thailand. Bouwman et al. (2019) found that the digitalization strategy of MSMEs in Europe influences organizational performance. The research by Tajudeen et al. (2019) revealed that the digitalization strategy of companies in Malaysia affects organizational performance. Of the eight research documents, only the study by Tajudeen et al. (2019) who focused on MSMEs but is analyzed and helped to develop a research framework, since it is still in the business research area, came from a reputable journal, was fairly recent, and researches constructs relevant to the research framework. 


\section{Results and discussion}

Table 1 shows the information on the 16 Scopus research publications that compose the theoretical framework. As can be seen from the table, they come from quality sources (indexed by Scopus Q1 and WoS SSCI); but there are only three documents that are not indexed by WoS and one document that has not Scopus indexed. These three documents by researched by Najib and Faham (2020); Somjai et al. (2019), and Tajudeen et al. (2019) will remain the basis for the preparation of the research framework, keeping in mind that there is a research gap that is quite logical to underlie the influence between constructs as part of the research framework.

Summative content analysis for the 16 documents in Table 2 was used as a basis for preparing propositions based on the research gap of each to produce a comprehensive, logical, and coherent research framework. The proposed research framework aligns with LePine and King (2010), which states that the literature review elaborates the relationship between constructs according to theory.

Table 1 Information on Scopus indexed research publication documents that compose the theoretical framework

\begin{tabular}{|c|c|c|c|c|c|}
\hline No. & Topic & Authors, Year & Journal Name & $\begin{array}{l}\text { Quartile Scopus } \\
\text { according to } \\
\text { scimagojr.com version } \\
2020\end{array}$ & WoS Index \\
\hline 1 & \multirow[t]{8}{*}{ GE } & Sobaih et al. (2020) & Sustainability & Q1 & $\mathrm{SSCI} \& \mathrm{SCIE}$ \\
\hline 2 & & Chung (2020) & $\begin{array}{l}\text { Journal of Hospitality } \\
\text { Marketing and Manage- } \\
\text { ment }\end{array}$ & Q1 & $\mathrm{SSCl}$ \\
\hline 3 & & Asadi et al. (2019) & \multirow{2}{*}{$\begin{array}{l}\text { Resources, Conservation } \\
\& \text { Recycling }\end{array}$} & \multirow[t]{2}{*}{ Q1 } & \multirow[t]{2}{*}{$\mathrm{SSCl}$} \\
\hline 4 & & Singh et al. (2018) & & & \\
\hline 5 & & $\begin{array}{l}\text { Yarimoglu and Binboga } \\
\text { (2019) }\end{array}$ & \multirow[t]{4}{*}{$\begin{array}{l}\text { Business Strategy and } \\
\text { the Environment }\end{array}$} & \multirow[t]{4}{*}{ Q1 } & \multirow[t]{4}{*}{$\mathrm{SSCl}$} \\
\hline 6 & & Yen (2018) & & & \\
\hline 7 & & Han et al. (2018) & & & \\
\hline 8 & & Wong et al. (2018) & & & \\
\hline 9 & \multirow[t]{3}{*}{ Digitalization } & Garzella et al. (2021) & $\begin{array}{l}\text { Technology Analysis and } \\
\text { Strategic Management }\end{array}$ & Q2 & $\mathrm{SSCl}$ \\
\hline 10 & & Alraja et al. (2020) & $\begin{array}{l}\text { Bulletin of Electrical } \\
\text { Engineering and Infor- } \\
\text { matics }\end{array}$ & Q3 & $\mathrm{ESCl}$ \\
\hline 11 & & Najib and Fahma (2020) & $\begin{array}{l}\text { International Journal on } \\
\text { Advanced Science, Engi- } \\
\text { neering and Information } \\
\text { Technology }\end{array}$ & Q3 & - \\
\hline 12 & & Irimiás and Mitev (2020) & Sustainability & Q1 & $\mathrm{SSCl} \& \mathrm{SCIE}$ \\
\hline 13 & & Khin and Ho (2019) & $\begin{array}{l}\text { International Journal of } \\
\text { Innovation Science }\end{array}$ & Q2 & $\mathrm{ESCl}$ \\
\hline 14 & & Somjai et al. (2019) & $\begin{array}{l}\text { International Journal of } \\
\text { Supply Chain Manage- } \\
\text { ment }\end{array}$ & - & - \\
\hline 15 & & Bouwman et al. (2019) & $\begin{array}{l}\text { Telecommunications } \\
\text { Policy }\end{array}$ & Q1 & SCIE \& SSCI \\
\hline 16 & & Tajudeen et al. (2019) & $\begin{array}{l}\text { Journal of Open Innova- } \\
\text { tion: Technology, Market, } \\
\text { and Complexity }\end{array}$ & Q2 & - \\
\hline
\end{tabular}




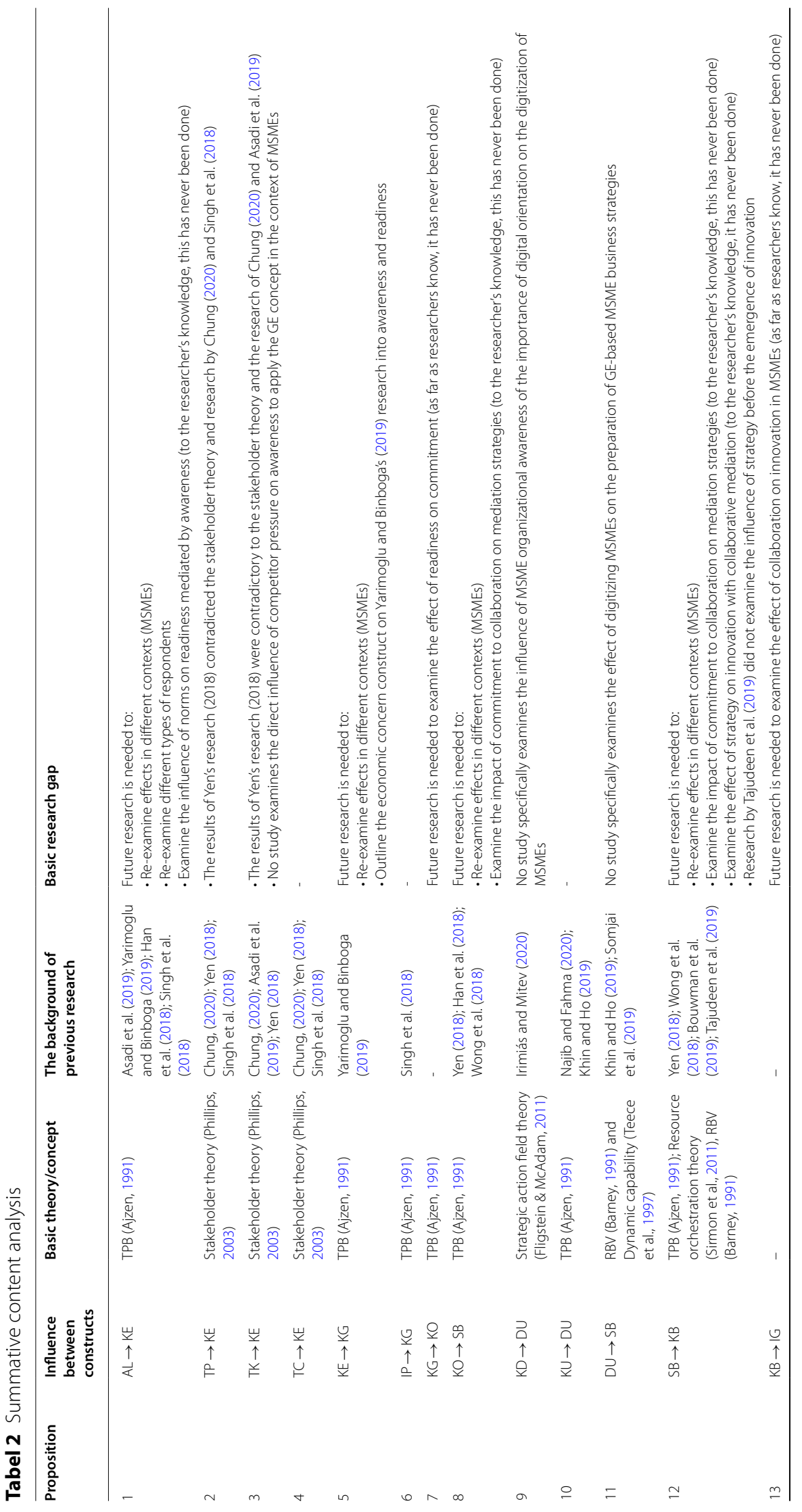




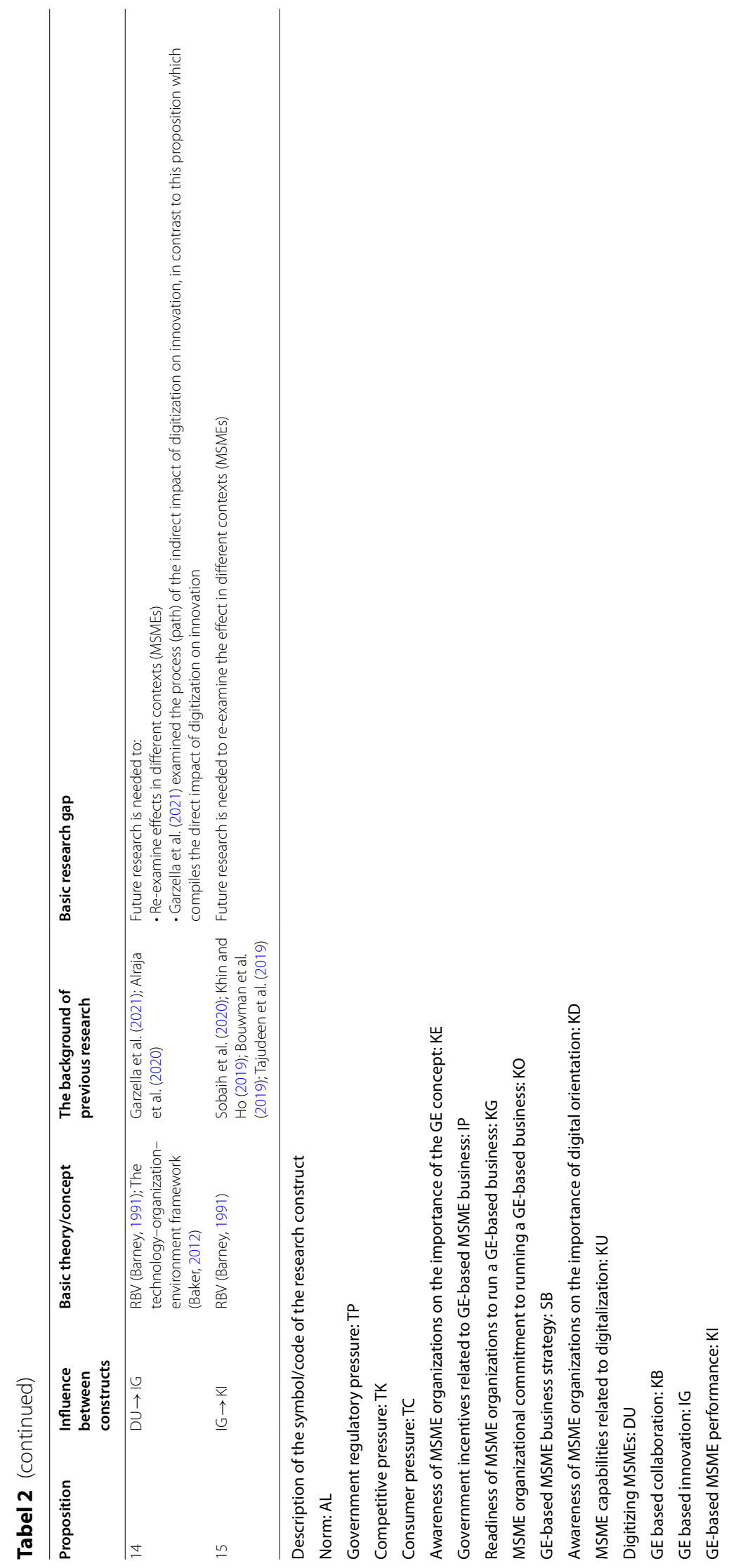


The research framework consists of 15 constructs and 15 propositions that form a logical and coherent process flow. Ontologically, this research framework means that GE requires a process for its constituent constructs for SMEs to perform well. Starting from the readiness of MSMEs to run a GE-based business, it affects commitment. Once MSMEs are committed to running a GE-based business, it will affect the formulation of a GE-based MSME business strategy. The GE-based MSME business strategy is also affected by the digitization of MSMEs, so the GE-based MSME strategy combines the GE concept itself and business digitization. The existence of a GE-based MSME business strategy and digitalization requires collaboration between MSME business stakeholders. The collaboration will lead to GE-based innovation, which improves GE performance.

Propositions 1 to 4 are related to the antecedents of MSME organizational awareness of the importance of the GE concept; that is, the understanding MSMEs have of the importance of the GE concept. Asadi et al. (2019), Yarimoglu and Binboga (2019), Han et al. (2018), Singh et al. (2018), Chung (2020) and Yen (2018) investigated the antecedents of organizational awareness of the importance of the GE concept. While previous studies-except Singh et al. (2018) did not examine an MSME-specific context, they investigated within a business context, so their findings remain quite relevant. MSMEs, especially owners and/or managers, need to be aware of the importance of implementing the GE concept. Four factors influence this awareness: norms, government regulations, competitor pressure, and consumer pressure; these are the important stakeholders for MSMEs.

Proposition 1 The influence of norms on MSME awareness of the importance of the GE concept. This proposition is based on the theory of planned behavior/TPB (Ajzen, 1991). According to TPB, a person behaves based on available information, and, being consciously motivated, and will consider the consequences of their behavior before deciding on a course of action. Asadi et al. (2019) stated that personal norms significantly mediate the influence of subjective norms on adopting green IT for decision-makers of manufacturing companies in Malaysia. Meanwhile, Yarimoglu and Binboga (2019) found that altruism significantly affects ecologically conscious consumer behavior in Turkey. Altruism is an attitude based on personal norms, which encourages an individual to implement green behavior practices consciously. Han et al. (2018) found that social norms significantly affect the sense of obligation to take pro-environmental actions for cruise ship passengers. Similarly, Singh et al. (2018) found that social pressure substantially affects the readiness of MSMEs in India to implement a circular economy. Social pressure is a form of pressure from social norms that provide perception for business organizations to tend to behave in a certain way, according to what is considered proper by society. The circular economy is part of the green economy (D'Amato et al., 2017). Norms refer to the do's and don'ts for business organizations to behave in a certain way. In this case, behavior is related to the awareness of business organizations (owners and/or managers) to run their business in line with the GE concept. With the existence of personal, subjective, or social norms related to GE, MSMEs are aware of the importance of implementing GE practices. 
Proposition 2 The effect of government regulatory pressure on MSME awareness of the importance of the GE concept. This proposition is based on stakeholder theory (Phillips, 2003) which states that business organizations must know and fulfill stakeholders' interests and involve them in strategic decisions (Miles, 2012). Cung (2020) found that stakeholders (including the government) played a significant role in increasing GEs orientation from a marketing perspective for GE-based hotels in Taiwan. By contrast, Yen (2018) stated that regulatory (government) pressure has no significant effect on the commitment of top management members to implement GE for electronic companies in Taiwan. Meanwhile, Singh et al. (2018) found that social pressure significantly influences MSME readiness in India to implement a circular economy. In the social pressure construct, there is also an element of regulatory pressure (government), as one of the roles of the government is to pressure businesses, including MSMEs, to be aware of the importance of implementing GE. However, the results of Yen's (2018) do not support the stakeholder theory as well as those of Chung (2020) and Singh et al. (2018), so that there is a research gap relating to the influence of government regulatory pressure on the awareness of MSMEs in terms of the importance of the GE concept.

Proposition 3 The effect of competitive pressure on MSME awareness of the importance of the GE concept. This proposition is based on stakeholder theory (Phillips, 2003). Chung (2020) found that stakeholders (including competitors) significantly increased GE's orientation from a marketing perspective for GE-based hotels in Taiwan. Asadi et al. (2019) stated that managerial interpretation significantly mediates the effect of competitive advantage on adopting green IT for decision-makers of manufacturing companies in Malaysia. Thus, indirectly, increasingly fierce competition (pressure from competitors who have previously implemented the GE concept) has made business organizations aware of implementing the GE concept. Yen (2018) stated that competitive pressure has no significant effect on top management's commitment to implementing GE for electronics companies in Taiwan. Competitors who first successfully apply the GE concept to their business can pressure MSMEs to be aware of the importance of a GE-based business. The gap in the research that underlies this proposition is the contradiction between Yen (2018)'s study on stakeholder theory and Chung's (2020) and Asadi et al. (2019). No study has been conducted that explicitly explains the influence of competitor pressure on the awareness of MSMEs about the importance of the GE concept.

Proposition 4 The effect of consumer pressure on MSME awareness of the importance of the GE concept. As above, this proposition is based on stakeholder theory (Phillips, 2003). Chung (2020) found that stakeholders (including consumers) significantly increase GE's orientation from a marketing perspective for GE-based hotels in Taiwan. Meanwhile, Yen (2018) revealed that consumer pressure significantly affects top management's commitment to implementing GE for electronics companies in Taiwan. Singh et al. (2018) found that social anxiety significantly influences MSMEs readiness in India to implement a circular economy. The social pressure construct also involves a market (consumer) element. Consumers who are aware of the importance of the GE concept play a role in pressuring businesses, including MSMEs, to be mindful of implementing GE. 
Propositions 5 and 6 continue the process. If MSMEs are aware of the importance of implementing the GE concept for their business, they will continue to be prepared to implement the GE concept.

Proposition 5 The influence of MSME awareness of the importance of the GE concept on the readiness of MSMEs to run a GE-based business. This proposition is based on the theory of planned behavior/TPB (Ajzen, 1991). Yarimoglu and Binboga (2019) stated that economic concern significantly affects ecologically conscious consumer behavior in Turkey. Economic concern is consumer awareness of the importance of environmental sustainability, which aims to conserve the environment. This awareness and readiness underlie the emergence of the influence of MSME awareness of the importance of the GE concept on the readiness of MSME organizations to run a GE-based business. This proposition describes the ecological concerns in Yarimoglu and Binboga (2019) as differentiating between awareness and readiness, thus filling a research gap. In addition, thus far, no study has examined the influence of MSME awareness of the importance of the GE concept on the readiness of MSMEs to run a GE-based business.

Proposition 6 The effect of government incentives related to GE-based MSMEs on the readiness of MSME organizations to run GE-based businesses. This proposition is based on the theory of planned behavior/TPB (Ajzen, 1991). Singh et al. (2018) found that GE incentives have a significant effect on the readiness of MSMEs in India to implement a circular economy. The government provides incentives as an external stimulus for business organizations, including MSMEs, to implement GE. This incentive is important, because in MSMEs, including micro-enterprises, the financial conditions are usually not "bankable" related to capital; thus, incentives can help micro-enterprises a lot to apply the GE concept in their business ventures.

Once MSMEs are ready to implement the GE concept, commitment is required. After the owner and/or manager's commitment, it continues to develop a GE-based MSME business strategy.

Proposition 7 The effect of MSME readiness on MSME commitment to run a GE-based business. This proposition is based on the theory of planned behavior/TPB (Ajzen, 1991). If MSMEs are ready to implement the GE concept, they will seriously implement it. No study has found the effects of readiness on commitment in the context of GE implementation in MSMEs. Therefore, conceptually, this is a theoretical novelty.

Proposition 8 The effect of MSME commitment to running a GE-based business on the GE-based MSME business strategy. This proposition is based on the theory of planned behavior/TPB (Ajzen, 1991). Yen (2018) stated that top management commitment significantly affects green collaboration to implement GE in electronic companies in Taiwan. Han et al. (2018) indicated that green loyalty is a consumer's commitment to behave according to the GE concept, which results in profits for the business. Wong et al. (2018) explained that sustainable supply chain development/SSCD affects the performance of manufacturing companies in Thailand. SSCD is formed from internal sustainable development, sustainable supplier development, and sustainable customer development. This 
proposition tends to internal sustainable development, a business strategy based on the environment, and internal collaboration. From research by Yen (2018) and Han et al. (2018) placed more emphasis on the concept of commitment. By contrast, Wong et al. (2018) placed more emphasis on the strategy side. There has also been no research on the effect of MSME commitment to running a GE-based business on GE-based MSME business strategy.

Propositions 9,10 and 11 explain that GE-based business strategies are not only formed from commitments but also the role of digitizing business organizations. In the current era of society 5.0, MSMEs are strongly influenced by digital technology (Salgues, 2018). The digitization of MSMEs is affected by the awareness of MSMEs' importance and digitization readiness.

Proposition 9 The influence of MSME awareness of the importance of digital orientation towards their digitization. This proposition is based on the strategic action field/SAF theory (Fligstein \& McAdam, 2011). SAF defines the company as a business organization that strategically interacts with the business ecosystem (competitors, market forces, and social movements). Irimiás and Mitev (2020) stated that the digitization of SMEs in Hungary could become leverage. It is necessary to have a common understanding of the benefits of digitization. Digitalization means that MSMEs need to be aware that digitalization is important and has a good impact. The empirical results of Irimiás and Mitev (2020) found that change management has a significant effect on digital maturity. This is a research gap that underlies the need for research on the influence of MSME awareness of the importance of digital orientation towards digitization. Regarding change management in Irimiás and Mitev's (2020) research, it is necessary to change the mindset of MSME business owners to realize the importance of digitization for their business.

Proposition 10 The influence of the capabilities of digitization on the digitization of MSMEs. This proposition is based on the theory of planned behavior/TPB (Ajzen, 1991). Najib and Fahma (2020) found a significant effect of attitude towards using digital payment for SME consumers in Indonesia. Najib and Fahma's research (2020) is related to the digitalization of MSMEs in finance (digital payments). In contrast, Khin and Ho (2019) found the effect of digital capability on digital innovation in SMEs for the ICT sector in Malaysia. No study has yet examined the influence of the ability of MSMEs on achieving digitization. Najib and Fahma (2020) and Khin and Ho (2019) studied the digital capability and MSMEs' ability internally to realize digitization.

Proposition 11 The effect of MSME digitization on GE-based MSME business strategy. This proposition is based on the theory of RBV (Barney, 1991) and dynamic capability (Teece et al., 1997). RBV states that, to be competitive, business organizations must have valuable, unique resources, that are difficult to imitate and challenging to replace. Meanwhile, dynamic capability means that, to become and remain competitive, organizations are advised to have new capabilities. This new capability can help a company integrate, build, and rearrange its internal and external competencies to respond to the dynamics of its environment. Khin and Ho (2019) found the influence of digital capability is a dynamic 
capability for digital innovation in SMEs for the ICT sector in Malaysia, and thus, digital innovation is part of the business strategy. In Khin and Ho's research (2019), digital innovation is a primary strategic tool for business organizations, where it is a form of resource. Digital innovation mediates digital capability and digital orientation towards organizational performance. Somjai et al. (2019) found that digitization did not significantly moderate the effect of supply chain negotiation and SMEs' performance. Trade digitization is a strategic action for business organizations related to digital transformation (efforts to digitize SMEs). This could create a research gap to examine the role of digitization as an antecedent to GE's business strategy. No specific study has been conducted on the direct effect of digitizing MSMEs on GE-based MSME business strategies.

The following propositions (12-15) continue the influence of GE's MSME business strategy on GE's collaboration, innovation, and performance. To realize GE-based business performance, MSMEs must produce innovations related to GE. GE-related innovations arise from collaboration and digitization. In this case, digitalization plays an important role directly and indirectly in GE-related innovations.

Proposition 12 The effect of GE-based MSME business strategy on GE-based collaboration. This proposition is based on several theories, including TPB (Ajzen, 1991); resource orchestration theory (Sirmon et al., 2011), and RBV (Barney, 1991). Resource orchestration theory is a refinement of the RBV that states that business organizations' actions to compose, combine, and utilize organizational resources (knowledge, capability, IT) make the organization competitive. Yen (2018) stated that top management commitment and customer pressure significantly affect green collaboration to implement GE in electronic companies in Taiwan. Wong et al. (2018) explained that sustainable supply chain development/SSCD affects the performance of manufacturing companies in Thailand. SSCD is formed from internal sustainable development, sustainable supplier development, and sustainable customer development. This proposition tends to internal sustainable development, a business strategy based on the environment, and internal collaboration. Bouwman et al. (2019) examined business model strategy implementation practices, namely, how business models are implemented through organizational strategies for SMEs in Europe. Bouwman et al. (2019) explained that digitalization plays a role in changing business model innovation. Business model innovation is an organizational strategy, and in the business model, there is a collaboration between various levels in the organization. Therefore, a strategy is needed to collaborate with various parties. For example, Tajudeen et al. (2019) examined open innovation strategy, technology scouting through social media, and digital vision as antecedents of innovation performance in Malaysia.

Regarding this proposition, open innovation includes elements of strategy and technology scouting through social media, which contains elements of collaboration. Tajudeen et al. (2019) did not examine the influence of the strategy before innovation. To realize a GE-based business strategy, collaboration with various external and internal parties is needed. MSMEs need a GE business strategy that results in collaboration. 
Proposition 13 The effect of collaboration on GE-based innovation. As far as the authors are aware, the effect of GE-based collaboration on GE-based innovation has not been studied before. Therefore, this proposition is also a novelty. If there is a collaboration between various parties related to GE-based business strategies, it will bring about GE-related innovations. This is quite logical, because, in collaboration, knowledge sharing takes place, which has the potential to create new ideas as the basis for innovations related to GE.

Proposition 14 The effect of digitizing MSMEs on GE-based innovation. This proposition is based on the RBV theory (Barney, 1991) and the technology-organizationenvironment (TOE) framework (Baker, 2012). TOE discusses technology adoption in organizations and explains how technological innovation is influenced by technological, organizational, and environmental contexts. Garzella et al. (2021) examined digitalization boundaries that affect business model innovation for SMEs in Italy. Research by Garzella et al. (2021) stated that digitalization cannot directly affect innovation but must is subject to size and capability limits (technology, culture, and relations). Meanwhile, Alraja et al. (2020) found that SME digitization is significantly affected by technology, organization, and environment for SMEs in Oman. Alraja et al. (2020) studied the digitization of SMEs and, from the research of Garzella et al. (2021), examined the process (path) of the indirect influence of digitization on innovation. Then a logical relationship can be drawn up if the digitization of MSMEs directly affects GE-based innovation. The digitization of MSMEs is related to various digital technologies used by MSMEs that allow the emergence of new ideas related to the implementation of GE, one of which comes from experiences (best practices) that various parties have carried out.

Proposition 15 The effect of GE-based innovation on GE-based MSME performance. This proposition is based on the RBV theory (Barney, 1991). Sobaih et al. (2020) found a significant effect between green innovation on environmental performance. Khin and Ho (2019) found that digital innovation had a significant effect on the performance of SMEs for the ICT sector in Malaysia. Similarly, Bouwman et al. (2019) found that innovativeness has a significant effect on the overall performance of SMEs in Europe; while Tajudeen et al. (2019) found that innovation performance significantly affects company performance in Malaysia. A proposition is drawn from the previous three studies that GE-based innovation for MSMEs influences GE-based performance for MSMEs; the more innovative the MSMEs, the better their performance in relation to GE they will be.

Based on propositions 1 to 15 for each influence between constructs, a research framework is arranged in Fig. 2.

In Fig. 2, it can be seen that before achieving GE based performance, there must first be GE based innovation. GE-based innovation is an innovation that considers economic, social and environmental factors. GE-based innovation is linked to the Quintuple Helix-based innovation concept. Quintuple Helix is a refinement of the Quadruple Helix concept by adding natural environments (Carayannis \& Campbell, 2014; Carayannis \& Rakhmatullin, 2014; Carayannis et al., 2012, 2021; Grundel \& Dahlström, 2016). The Quadruple Helix only consists of four systems, including the 
higher education system, the economic system, the political system and the society system (Carayannis \& Campbell, 2009). The link between the GE-based innovation construct and the Quintuple Helix-based innovation specifically exists in the natural environment. Quintuple Helix-based innovations also contribute to realizing sustainable development (Carayannis et al., 2012) and society transformation related with bio economy or circular economy (Grundel \& Dahlström, 2016). Quintuple Helix-based innovation comes from knowledge production/research by higher education related to industry and government (Triple Helix) which is then applied so that it becomes a synergistic solution related to economy, social and environment. The innovation produced by MSME must be a form of innovation that produces a sustainable impact on the economy, society and the natural environment. Knowledge in the Quintuple Helix is a know-how cycle between its five constituent elements in sequence starting from the education system (the creation of knowledge of human capital); economic system (creating knowledge of economic capital); political system (creating knowledge of political and legal capital); society system (creation of knowledge information and social capital) and natural environment (creation of knowledge natural capital). Human capital knowledge; economic knowledge; political and legal knowledge; information and social knowledge and natural knowledge are five forms of knowledge that make up GE-based innovation. Collaboration between the five parties on the Quintuple Helix element is needed to produce knowledge synergies. For that we need a GEbased collaboration construct (it can be seen that there is a Fig. 2 that precedes the GE-based innovation construct). Furthermore, according to Carayannis et al. (2021) Quintuple Helix-based innovation is also related to digital transformation. In Fig. 2, the GE-based innovation construct is also preceded by a construct related to digitization, namely, digitizing MSME. Digitalization in MSME is formed by the construct of MSME awareness of the importance of digitization and MSME's capabilities related to digitization. Digitalization (technology digital) enables MSME to run its business in line with the GE and Quintuple Helix concepts.

\section{Conclusion}

Interestingly, the research framework shows a comprehensive process in which MSME performance appears from the GE perspective, which stems from readiness related to the GE concept and digitalization. To the authors' knowledge, the research framework formed is quite complex and lengthy, explaining the antecedents of GE's performance. The research framework consists of 15 constructs and 15 propositions that have never existed as far as the authors know. This research framework also introduced more specific novelties, namely, in proposition 7 (the influence of MSME organizational readiness to run a GE-based business on MSME commitment to run a GE-based business) and 13 (the influence of IG-based collaboration on GI-based innovation that does not yet exist in a GE performance antecedent research framework).

The research framework that results from this research contributes theoretically to the study of entrepreneurship in general and SMEs as a "small business" in particular. This research framework explains that for MSMEs to achieve GE performance, three main things are needed: GE-based innovation, MSME readiness to implement GE, and digitalization. Digitization plays an essential in GE-based MSME business strategy and 


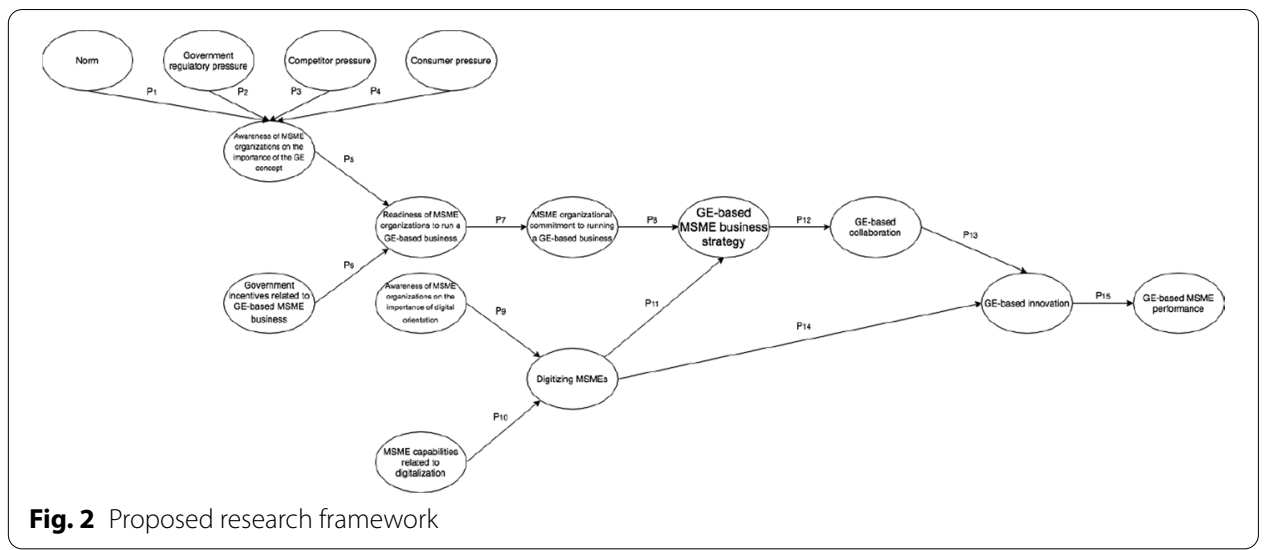

GE-based innovation. After MSMEs are ready to implement the GE concept, then they need commitment, strategy, and collaboration to produce innovation. The proposed research framework for MSMEs is also formed from seven theories of management and organization studies, including TPB (Ajzen, 1991), stakeholder theory (Phillips, 2003), strategic action field theory (Fligstein \& McAdam, 2011), RBV (Barney, 1991), dynamic capability (Teece et al. al., 1997), resource orchestration theory (Sirmon et al., 2011) and the technology-organization-environment framework (Baker, 2012). The seven theories that form the research framework explain the interrelationships between constructs. The theoretical implication of the formed research framework is related to the Quintuple Helix concept related to innovation. From the research framework, it can be seen that GE-based MSME innovation is formed by two main constructs, namely, collaboration and digitalization. These two constructs theoretically support the Quintuple Helix concept. In the Quintuple Helix concept, there are five main elements. There needs to be collaboration between the five elements of the Quintuple Helix starting from higher education, business, government, society and the natural environment. This collaboration is important, because each element produces knowledge where from the knowledge of each of these elements produces innovations, each of which contributes to sustainable development. Furthermore, digitalization can also play a role in realizing and accelerating the emergence of innovations that contribute to sustainable development. In the research framework, there are also several constructs other than those mentioned above which are related to the Quintuple Helix concept, namely, government and business (MSME).

The research implication for policy makers, in this case the government, is related to the government's role as seen in the construct of government regulatory pressure and government incentives related to GE-base MSME business. The government can put pressure through legal regulations for MSMEs to run their business according to the GE concept. This pressure is important, because it has the potential to accelerate MSME to change its business to be more oriented towards sustainable development. In the construct of government pressure that encourages MSMEs to run their business according to the GE concept, there are rewards in the form of incentives. With incentives for MSMEs that have run their business according to the GE concept, MSME will further enhance their business in 
accordance with the ideals of the GE concept and potentially stimulate many other MSMEs to adopt the GE concept in their business.

The research implication for practice is to provide advice for the government to prepare regulations related to the implementation of the GE concept for MSMEs in running their business. In the government regulation, it is necessary to state that there are incentives for MSMEs that have been proven to run their business according to the GE concept. The second practical implication is for MSME business managers to be able to transform their business according to the GE concept through digitalization.

The limitation of this research is the secondary data search method in the form of Scopus indexed research publication articles. Future research can improve the research framework based on secondary data derived from WoS indexed research publications. In addition, future research can complement this research framework, both in terms of adding propositions (relationships between constructs) and adding new constructs. The other limitation of this study is using only secondary data based on quantitative methods, specifically PLS-SEM (Partial Least Square-Structural Equation Modeling). This limitation opens up future research with the potential to conduct similar research using secondary data from a broader methodological point of view (qualitative, mixed-method, or quantitative other than PLS-SEM). The last limitation of this study only uses research documents published in scientific journals indexed in the English-language Scopus database. This opens up suggestions for future research to include languages outside English for a more complete secondary data source. The long path of influence to realize GE's performance conceptually requires empirical testing in various research contexts (location, sector, sample, respondents, and period). Finally, for empirical testing of future research quantitatively using structural equation modeling (SEM) analysis tools and other relevant methods.

\section{Acknowledgements}

LPPM Telkom University.

\section{Authors' contributions}

AP: conceptualization; formal analysis; investigation; methodology; resources; supervision; validation; visualization; writing — original draft; writing — review and editing. KS: formal analysis; validation; writing — review and editing. RS: writing - review and editing. YP: writing — review and editing. AAA: writing-review and editing. All authors are read and approved the final manuscript.

\section{Funding}

No funding was received.

Availability of data and materials

Not applicable.

\section{Declarations}

Competing interests

There is no conflict of interest.

\section{Author details}

'Business Administration Department, Telkom University, Bandung, Indonesia. ${ }^{2}$ Computer Engineering Department, Telkom University, Bandung, Indonesia. ${ }^{3}$ Central Bank of Indonesia, Jakarta, Indonesia.

Received: 6 October 2021 Accepted: 3 February 2022

Published: 15 February 2022 
Alraja, M. N., Hussein, M. A., \& Ahmed, H. M. S. (2020). What affects digitalization process in developing economies? An evidence from smes sector in oman. Bulletin of Electrical Engineering and Informatics, 10(1), 441-448. https://doi.org/10. 11591/eei.v10i1.2033

Asadi, S., Nilashi, M., Safaei, M., Abdullah, R., \& Saeed, F. (2019). Investigating factors influencing decision-makers 'intention to adopt Green IT in Malaysian manufacturing industry. Resources, Conservation \& Recycling, 148(April), 36-54. https://doi. org/10.1016/.j.resconrec.2019.04.028

Bag, S., Yadav, G., Wood, L. C., Dhamija, P., \& Joshi, S. (2020). Industry 4.0 and the circular economy: Resource melioration in logistics. Resources Policy, 68(June), 101776. https://doi.org/10.1016/j.resourpol.2020.101776

Baker, J. (2012). The technology-organization-environment framework. Information Systems Theory, 12, 231-245.

Barney, J. (1991). Firm resources and sustained competitive advantage. Journal of Management, 17(1), 99-120. https://doi.org/ $10.1177 / 014920639101700108$

Bouwman, H., Nikou, S., \& de Reuver, M. (2019). Digitalization, business models, and SMEs: How do business model innovation practices improve performance of digitalizing SMEs? Telecommunications Policy, 43(9), 101828. https://doi.org/10.1016/j. telpol.2019.101828

Breslin, D., \& Gatrell, C. (2020). theorizing through literature reviews: The miner-prospector continuum. Organizational Research Methods. https://doi.org/10.1177/1094428120943288

Breslin, D., Gatrell, C., \& Bailey, K. (2020). Developing insights through reviews: reflecting on the 20th anniversary of the International Journal of Management Reviews. International Journal of Management Reviews, 22(1), 3-9. https://doi.org/ 10.1111/ijmr.12219

Carayannis, E. G., Barth, T. D., \& Campbell, D. F. (2012). The quintuple helix innovation model: Global warming as a challenge and driver for innovation. Journal of Innovation and Entrepreneurship, 1(1), 2. https://doi.org/10.1186/2192-5372-1-2

Carayannis, E. G., \& Campbell, D. F. (2009). "Mode 3'and'Quadruple Helix": Toward a 21st century fractal innovation ecosystem. International Journal of Technology Management, 46(3-4), 201-234.

Carayannis, E. G., \& Campbell, D. F. (2014). Developed democracies versus emerging autocracies: Arts, democracy, and innovation in Quadruple Helix innovation systems. Journal of Innovation and Entrepreneurship, 3(1), 1-23. https://doi.org/10 1186/s13731-014-0012-2

Carayannis, E. G., \& Campbell, D. F. J. (2021). Democracy of climate and climate for democracy: The evolution of quadruple and quintuple helix innovation systems. Journal of the Knowledge Economy, 12(4), 2050-2082. https://doi.org/10.1007/ s13132-021-00778-x

Carayannis, E. G., Campbell, D. F. J., \& Grigoroudis, E. (2021). Helix trilogy: The triple, quadruple, and quintuple innovation helices from a theory, policy, and practice set of perspectives. Journal of the Knowledge Economy. https://doi.org/10. 1007/s13132-021-00813-X

Carayannis, E. G., \& Rakhmatullin, R. (2014). The quadruple/quintuple innovation helixes and smart specialisation strategies for sustainable and inclusive growth in Europe and Beyond. Journal of the Knowledge Economy, 5(2), 212-239. https://doi. org/10.1007/s13132-014-0185-8

Castro, G. D. R., Fernández, M. C. G., \& Colsa, A. U. (2021). Unleashing the convergence amid digitalization and sustainability towards pursuing the Sustainable Development Goals (SDGs): A holistic review. Journal of Cleaner Production, 280, 122204.

Cepeda Carrión, G., Henseler, J., Ringle, C. M., \& Roldán, J. L. (2016). Prediction-oriented modeling in business research by means of PLS path modeling: Introduction to a JBR special section. Journal of Business Research, 69(10), 4545-4551. https://doi.org/10.1016/j.jbusres.2016.03.048

Chung, K. C. (2020). Green marketing orientation: Achieving sustainable development in green hotel management. Journal of Hospitality Marketing and Management, 29(6), 722-738. https://doi.org/10.1080/19368623.2020.1693471

D’Amato, D., Droste, N., Allen, B., Kettunen, M., Lähtinen, K., Korhonen, J., Leskinen, P., Matthies, B. D., \& Toppinen, A. (2017). Green, circular, bio economy: A comparative analysis of sustainability avenues. Journal of Cleaner Production, 168, 716-734. https://doi.org/10.1016/j.jclepro.2017.09.053

Dutta, G., Kumar, R., Sindhwani, R., \& Singh, R. K. (2020). Digital transformation priorities of India's discrete manufacturing SMEs_-A conceptual study in perspective of Industry 4.0. Competitiveness Review, 30(3), 289-314. https://doi.org/10. 1108/CR-03-2019-0031

El-Kassar, A. N., \& Singh, S. K. (2019). Green innovation and organizational performance: The influence of big data and the moderating role of management commitment and HR practices. Technological Forecasting and Social Change, 144, 483-498.

Fligstein, N., \& McAdam, D. (2011). Toward a general theory of strategic action fields. Sociological Theory, 29(1), 1-26. https:// doi.org/10.1111/j.1467-9558.2010.01385.x

Garzella, S., Fiorentino, R., Caputo, A., \& Lardo, A. (2021). Business model innovation in SMEs: The role of boundaries in the digital era. Technology Analysis and Strategic Management, 33(1), 31-43. https://doi.org/10.1080/09537325.2020.1787374

Gatto, F. \& Re, I. (2021). Circular bioeconomy business models to overcome the valley of death. A systematic statistical analysis of studies and projects in emerging bio-based technologies and trends linked to the sme instrument support. Sustainability, 13(4), 1-37. https://doi.org/10.3390/su13041899

Grundel, I., \& Dahlström, M. (2016). A quadruple and quintuple helix approach to regional innovation systems in the transformation to a forestry-based bioeconomy. Journal of the Knowledge Economy, 7(4), 963-983. https://doi.org/10.1007/ s13132-016-0411-7

Hair, J. F., Sarstedt, M., Pieper, T. M., \& Ringle, C. M. (2012). The use of partial least squares structural equation modeling in strategic management research: A review of past practices and recommendations for future applications. Long Range Planning, 45(5-6), 320-340. https://doi.org/10.1016/j.lrp.2012.09.008

Han, H., Lee, M. J., \& Kim, W. (2018). Antecedents of green loyalty in the cruise industry: Sustainable development and environmental management. Business Strategy and the Environment, 27(3), 323-335. https://doi.org/10.1002/bse.2001

Irimiás, A., \& Mitev, A. (2020). Change management, digital maturity, and green development: Are successful firms leveraging on sustainability? Sustainability. https://doi.org/10.3390/SU12104019

Khin, S., \& Ho, T. C. F. (2019). Digital technology, digital capability and organizational performance: A mediating role of digital innovation. International Journal of Innovation Science, 11(2), 177-195. https://doi.org/10.1108/JIS-08-2018-0083 
Khurana, S., Haleem, A., Luthra, S., \& Mannan, B. (2021). Evaluating critical factors to implement sustainable oriented innovation practices: An analysis of micro, small, and medium manufacturing enterprises. Journal of Cleaner Production, 285, 125377. https://doi.org/10.1016/j.jclepro.2020.125377

Kirillova, O. V. (2017). Scopus database as a source of representing Bulgarian science to the international academic community: The present and future prospects. Digital Presentation and Preservation of Cultural and Scientific Heritage, VII, 69-78.

LePine, J. A., \& King, A. W. (2010). Editors' comments: Developing novel theoretical insight from reviews of existing theory and research. Academy of Management Review, 35(4), 506-509.

Loiseau, E., Saikku, L., Antikainen, R., Droste, N., Hansjürgens, B., Pitkänen, K., Leskinen, P., Kuikman, P., \& Thomsen, M. (2016). Green economy and related concepts: An overview. Journal of Cleaner Production, 139, 361-371. https://doi.org/10. 1016/j.jclepro.2016.08.024

Lumban Gaol, N. T. (2021). School leadership in Indonesia: A systematic literature review. Educational Management Administration \& Leadership. https://doi.org/10.1177/17411432211010811

Miles, J. A. (2012). Management and organization theory. Jossey-Bass.

Najib, M., \& Fahma, F. (2020). Investigating the adoption of digital payment system through an extended technology acceptance model: An insight from the Indonesian small and medium enterprises. International Journal on Advanced Science Engineering and Information Technology, 10(4), 1702-1708.

Paul, J., \& Criado, A. R. (2020). The art of writing literature review: What do we know and what do we need to know? International Business Review. https://doi.org/10.1016/j.ibusrev.2020.101717

Phillips, R. (2003). Stakeholder theory and organizational ethics. Berrett-Koehler Publishers.

Richter, N. F., Sinkovics, R. R., Ringle, C. M., \& Schlägel, C. (2016). A critical look at the use of SEM in international business research. International Marketing Review, 33(3), 376-404. https://doi.org/10.1108/IMR-04-2014-0148

Salgues, B. (2018). Society 5.0: Industry of the future, technologies, methods and tools. Wiley.

Singh, M. P., Chakraborty, A., \& Roy, M. (2018). Developing an extended theory of planned behavior model to explore circular economy readiness in manufacturing MSMEs, India. Resources, Conservation and Recycling, 135, 313-322.

Sirmon, D. G., Hitt, M. A., Ireland, R. D., \& Gilbert, B. A. (2011). Resource orchestration to create competitive advantage: Breadth, depth, and life cycle effects. Journal of Management, 37(5), 1390-1412. https://doi.org/10.1177/0149206310385695

Snyder, H. (2019). Literature review as a research methodology: An overview and guidelines. Journal of Business Research, 104(August), 333-339. https://doi.org/10.1016/j.jbusres.2019.07.039

Sobaih, A. E. E., Hasanein, A., \& Elshaer, I. (2020). Influences of green human resources management on environmental performance in small lodging enterprises: The role of green innovation. Sustainability (switzerland), 12(24), 1-19. https://doi. org/10.3390/su122410371

Somjai, S., Vasuvanich, S., Laosillapacharoen, K., \& Suteerachai, B. (2019). Governing role of trade digitalization in global supply chain finance, negotiation and SMEs performance. International Journal of Supply Chain Management, 8(5), 660.

Tajudeen, F. P., Jaafar, N. I., \& Sulaiman, A. (2019). External technology acquisition and external technology exploitation: The difference of open innovation effects. Journal of Open Innovation: Technology, Market, and Complexity, 5(4), 5-7. https:// doi.org/10.3390/joitmc5040097

Teece, D. J., Pisano, G., \& Shuen, A. (1997). Dynamic capabilities and strategic management. Strategic Management Journal, 18(7), 509-533.

UNEP. (2011). Green economy. https://www.unep.org/explore-topics/green-economy

Webster, J., \&Watson, R. T. (2002). Analyzing the past to prepare for the future: Writing a literature review. MIS Quarterly, 26(2), xiii-xxiii.

Wong, C. W. Y., Wong, C. Y., \& Boon-itt, S. (2018). How does sustainable development of supply chains make firms lean, green and profitable? A resource orchestration perspective. Business Strategy and the Environment, 27(3), 375-388. https://doi. org/10.1002/bse.2004

Yang, Z., Sun, J., Zhang, Y., \& Wang, Y. (2017). Green, green, it's green: A triad model of technology, culture, and innovation for corporate sustainability. Sustainability, 9(8), 1369. https://doi.org/10.3390/su9081369

Yarimoglu, E., \& Binboga, G. (2019). Understanding sustainable consumption in an emerging country: The antecedents and consequences of the ecologically conscious consumer behavior model. Business Strategy and the Environment, 28(4), 642-651. https://doi.org/10.1002/bse.2270

Yen, Y. X. (2018). Buyer-supplier collaboration in green practices: The driving effects from stakeholders. Business Strategy and the Environment. https://doi.org/10.1002/bse.2231

Zhan, Y., Tan, K. H., Ji, G., Chung, L., \& Chiu, A. S. F. (2018). Green and lean sustainable development path in China: Guanxi, practices and performance. Resources, Conservation and Recycling, 128, 240-249. https://doi.org/10.1016/..resconrec. 2016.02.006

\section{Publisher's Note}

Springer Nature remains neutral with regard to jurisdictional claims in published maps and institutional affiliations. 